\title{
RA?EGA
}

O ESPACYO GEOGRÁFICO EM ANÁLISE

\section{O CENTRO DA CIDADE E AS NOVAS ÁREAS DE CENTRALIDADE NA CIDADE MÉDIA DE JUAZEIRO DO NORTE/CE ${ }^{1}$}

\section{THE CENTRE AND NEW AREAS OF CENTRALITY IN THE MID- SIZED CITY OF JUAZEIRO DO NORTE/CE}

\author{
Cláudio Smalley Soares Pereira \\ Doutorando em Geografia pela Universidade Estadual Paulista Júlio de Mesquita Filho (UNESP) \\ Faculdade de Ciências e Tecnologia de Presidente Prudente \\ Presidente Prudente, SP \\ e-mail: clasmalley@hotmail.com
}

\section{Recebido em: 31/03/2014}

Aceito em: 06/02/2015

\section{Resumo}

O presente artigo discute a redefinição da centralidade urbana na escala da cidade. Tomando a cidade de Juazeiro do Norte como objeto de análise empírica, são abordadas questões conceituais sobre o centro da cidade e o surgimento de novos espaços de concentração de comércio e serviços para além do centro tradicional/principal a partir de três atividades econômicas específicas: lojas de eletrodomésticos, super e hipermercados associados ou não a shopping centers, e serviços bancários. Estes novos espaços expressam centralidades diferentes e mantêm "relações" diversas com o centro da cidade, relações estas que são apreendidas a partir das práticas espaciais dos citadinos referentes ao consumo, que acabam por hierarquizar e articular os diferentes espaços de acordo com as suas necessidades. A pesquisa revelou que as novas lógicas locacionais dos empreendimentos comerciais e de serviços na cidade de Juazeiro do Norte seguem a mesma lógica de muitas das cidades médias brasileiras, com a forte participação de agentes econômicos na transformação e expansão da cidade. O fechamento de

\footnotetext{
${ }^{1}$ Esse texto é composto de algumas reflexões que foram desenvolvidas em pesquisa de mestrado do autor deste artigo, com apoio financeiro da Fundação de Amparo à Pesquisa do Estado de São Paulo (FAPESP).
} 


\title{
O CENTRO DA CIDADE E AS NOVAS ÁREAS DE CENTRALIDADE NA CIDADE MÉDIA DE JUAZEIRO DO NORTE/CE
}

diversas lojas do centro da cidade juntamente com o aumento do preço do solo urbano são resultados da produção capitalista da cidade e da lógica na qual o espaço urbano vem sendo estruturado nas últimas décadas. Conclui-se que o espaço urbano de Juazeiro do Norte é reestruturado a partir das estratégias na localização dos empreendimentos que expressam centralidade para toda a cidade e além dela, como shopping centers e hipermercados, proporcionando alterações nas práticas espaciais.

Palavras-chave: produção do espaço urbano, setor terciário, reestruturação da cidade.

\begin{abstract}
This paper discusses the urban centrality redefinition on the city scale. The Juazeiro do Norte city in the Ceará State - Brazil, was the study object and the conceptual questions regarding the central urban areas, and the new areas emergence concentration of trade and services beyond the downtown from three specific economic activities are addressed: appliance stores, super and hypermarkets (associated with shopping centers or not), and banks. These new areas express different centralities and maintain various relationships with the downtown and central urban areas. These relationships, which are seized from the spatial practices of urban people related to consumption, which ultimately prioritize and articulate any differents spaces according to their needs. The research revealed that the new locational logic of commerce and services in the municipality of Juazeiro do Norte keeps the same logic as many other medium-sized cities in Brazil, with economic agents playing an important role in the process of transformation and expansion in the city. The closing of many shops in the center of the city occurred with the increase in urban land prices and showed that this process is the result of capitalist production in the city and the logic the use of urban space has en structured in recent decades. We concluded that urban space Juazeiro is restructured from the location strategies of enterprises expressing centrality to the entire city and beyond, such as shopping malls and hypermarkets, providing changes in spatial practices.
\end{abstract}

Keywords: production of urban space, tertiary sector, restructuring the city.

\section{INTRODUÇÃO}

O processo de urbanização no/do Brasil dos últimos quarenta anos é o resultado de intensas e complexas interações entre as dimensões econômica, política e social em/entre diferentes escalas geográficas. Diante disso, o pensar a respeito da cidade e do urbano no mundo contemporâneo e suas manifestações na 
formação social brasileira e nas formações socioespaciais intrínsecas a ela instigam os estudiosos a refletir sobre questões as mais diversas.

A temática da centralidade urbana tem sido bastante explorada pelos estudiosos do fenômeno urbano. Esta temática, embora já bastante discutida, ainda estimula a reflexão e o debate, sobretudo, pela importância do centro para qualquer cidade.

Com os processos de redefinição da centralidade urbana resultantes de novas formas de produção do espaço a partir de processos engendrados nas escalas mais amplas e suas articulações em outras escalas, a relação centroperiferia passou a ter novos conteúdos e significados primeiramente nas metrópoles e posteriormente nas cidades médias, estas recebendo rebatimentos espaciais mais tardiamente, como é o caso da cidade aqui estudada.

Juazeiro do Norte é uma cidade que está localizada no Sul do Estado do Ceará, na região do Cariri (figura 1). No último Censo do IBGE, contava com uma população de 249.940 habitantes, dos quais 240.128 urbanos e destes, 238.938 vivendo na sede no município, caracterizando uma taxa de urbanização de $96 \%$ (IBGE, 2010). É uma importante cidade da rede urbana cearense e exerce forte influência regional, tanto em cidades do mesmo estado como em algumas dos estados vizinhos (IBGE, REGIC, 2008).

Devido sua centralidade na escala da rede urbana ser expressiva, ela pode ser entendida como uma cidade média, que são "aquelas que desempenham papéis de intermediação em suas redes urbanas" (SPOSITO, 2010b, p. 1). O processo de estruturação da cidade de Juazeiro do Norte vem nas últimas décadas vem ganhando notoriedade devido a presença de formas espaciais que até então não faziam parte da paisagem urbana. Essas novas formas espaciais, em sua maioria sob o domínio dos agentes econômicos em escala nacional e internacional, têm condicionado novos processos e práticas espaciais por parte dos citadinos. 


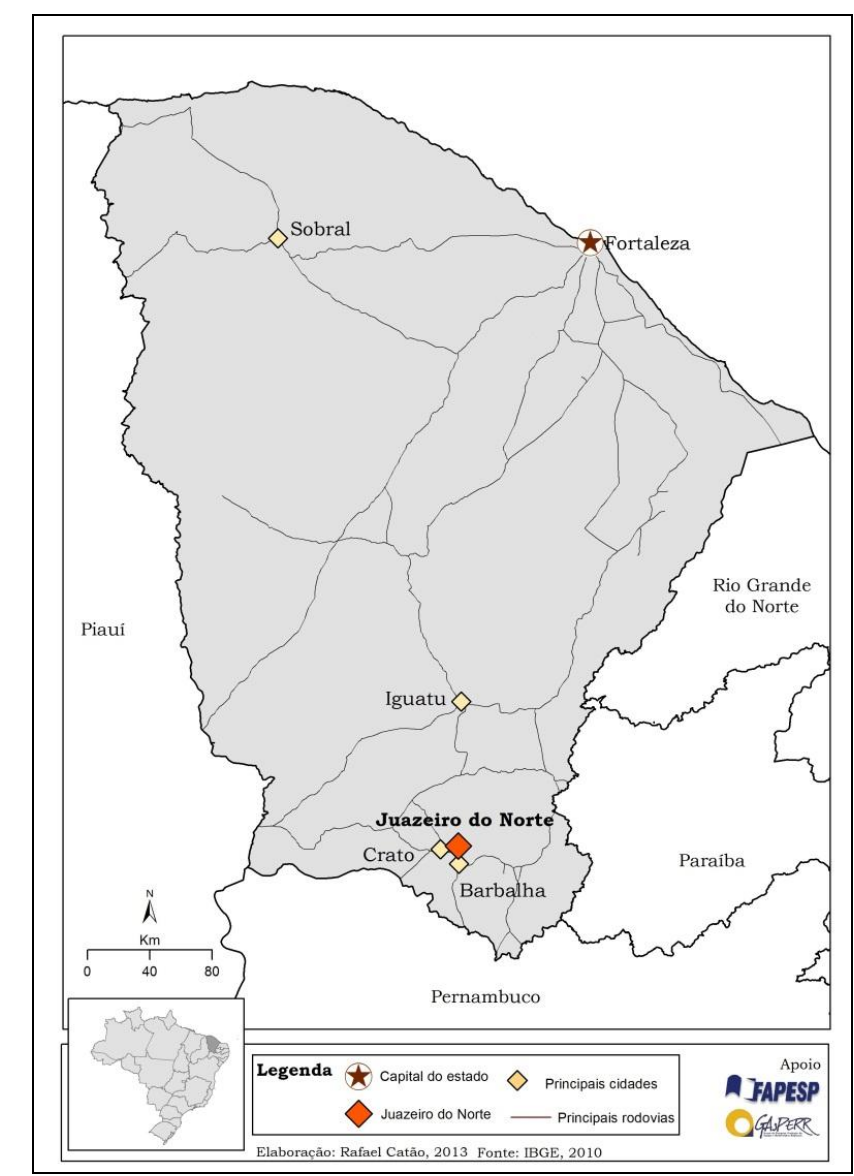

Figura 1: Ceará. Situação geográfica no Estado do Ceará de Juazeiro do Norte e as principais cidades.

Fonte: IBGE (2013)

Nesse contexto, as estratégias de localização dos empreendimentos por parte dos agentes econômicos têm mostrado que as tendências da estruturação recente nesta cidade estão ligadas a um processo de redefinição da centralidade urbana, sobretudo na escala do espaço urbano, denunciando uma dinâmica urbana com características de um processo de reestruturação da cidade.

Este artigo discute a redefinição da centralidade na escala da cidade. Tomando a cidade de Juazeiro do Norte como referência, são abordadas questões conceituais sobre o centro da cidade e o surgimento de novas áreas de concentração de comércio e serviços para além do centro tradicional/principal a partir de três atividades econômicas específicas: lojas de eletrodomésticos, super e hipermercados associados ou não a shopping centers, e serviços bancários. Estes 
novos espaços expressam centralidades diferentes e mantêm relações diversas com o centro da cidade, relações estas que são apreendidas a partir das práticas espaciais dos citadinos referentes ao consumo, que acabam por hierarquizar e articular os diferentes espaços de acordo com as suas necessidades de consumo.

\section{MATERIAIS E MÉTODOS}

Para a realização da pesquisa, alguns procedimentos metodológicos foram necessários, visto que se entende aqui que tais procedimentos facilitam a compreensão do real. Neste sentido, optou-se por alguns procedimentos de caráter tanto quantitativos como qualitativos.

Os procedimentos que foram operacionalizados podem ser classificados em dois grupos: a) os referentes ao trabalho de campo, visto que este se caracteriza como uma das principais ferramentas de pesquisa do geógrafo (KAYSER, 2006), e b) os trabalhos de gabinete, com revisão bibliográfica - autores ligados à discussão do centro da cidade e da centralidade urbana - e a coleta de dados secundários produzidos por instituições as mais diversas, como o IBGE, o Instituto Brasileiro de Executivos do Varejo e do Mercado de Consumo (IBEVAR), além da pesquisa documental referente a jornais, em busca de informações que contribuíssem para a realização da pesquisa.

No plano das pesquisas de campo, foi realizado um levantamento dos estabelecimentos comerciais e de serviços, buscando identificar e "delimitar" as áreas com expressão de centralidade, conforme será visto no decorrer do texto. Usou-se, então, um recorte delimitado para a seleção que abrangeriam as áreas e/ou eixos que apresentam mais de $70 \%$ de usos do solo ocupados por atividades comerciais e de serviços. Isso foi realizado a partir de visitas de campo e reconhecimento das áreas/eixos no sentido de delimitar quais seriam as ruas em 


\section{O CENTRO DA CIDADE E AS NOVAS ÁREAS DE CENTRALIDADE NA CIDADE MÉDIA DE JUAZEIRO DO NORTE/CE}

que apresentavam a presença deste percentual de atividades de forma concentrada ${ }^{2}$.

Juntamente a isto o levantamento fotográfico dos estabelecimentos foi também importante, pois permitiu uma melhor apresentação dos dados produzidos em campo no sentido de registrar transformações na paisagem urbana bem como da entrada de novos agentes econômicos, sobretudo os ligados ao setor terciário. Isso possibilitou uma melhor apreensão da produção das novas áreas de centralidade bem como da própria dinâmica do centro da cidade.

Não se pode esquecer dos jornais, que foram imprescindíveis para a pesquisa. A sua importância se dá pelo fato deles conterem informações de difícil acesso, como entrevistas aos presidentes de grandes empresas do setor supermercadista, por exemplo, bem como conterem dados que, depois de sistematizados - apresentados aqui em formas de quadros e tabelas - tornaram o objeto empírico inteligível.

\section{RESULTADOS E DISCUSSÃO}

\section{1. $O$ centro da cidade e a produção de novas áreas de centralidade}

O centro da cidade é caracterizado na ampla bibliografia especializada como um espaço dotado de qualidades que o diferenciam das demais áreas da cidade (LABASSE, 1965, 1970; LÉVY, 1986; MONNET, 2000; SANTOS, 1959; SZULC, 1975; TOURINHO, 2004; SALGUEIRO, 1996; SPOSITO, 2010a; VILLAÇA, 2009). É nesta área em que os valores e funções urbanos, o preço do solo, a densidade da atividade comercial e de serviços, a presença de estabelecimentos de lazer e diversão diurna e noturna, de edifícios públicos, do anonimato e da liberdade se apresentam com maior intensidade (RENDU, 1970).

Para Labasse (1970, p. 8), "o centro é de fato um pouco de tudo de uma só vez, quer dizer, uma reunião das mais altas manifestações da vida de relações,

\footnotetext{
${ }^{2}$ A escolha deste percentual de atividades foi feita por aproximação, isto é, sem o uso de uma metodologia já testada. Mas ela, contudo, identifica-se com metodologias já clássicas para o estudo dos centros das cidades, como a de Murphy e Vance (1954), que é citada em Beaujeu-Garnier (1965) juntamente com outras, e que é utilizada por Ribeiro Filho (2004). Outro trabalho que apresenta diversas metodologias é o de Pernelle (1970).
} 


\section{PEREIRA, C. S. S. \\ O CENTRO DA CIDADE E AS NOVAS ÁREAS DE CENTRALIDADE NA CIDADE MÉDIA DE JUAZEIRO DO NORTE/CE}

segundo o princípio de nodalidade que está no coração da noção de cidade". O autor continua, afirmando que "para o geógrafo, o centro é em definitivo o lugar ou o ponto de convergência onde a cidade exerce e afirma o poder e de onde se dirige uma imagem que exalta a radiação" (LABASSE, 1970, p. 8) ${ }^{3}$. O centro da cidade, nesta perspectiva, não pode ser entendido apenas pelo ponto de vista funcional, embora este seja um elemento essencial. Como escreveu o próprio Labasse (1970, p. 14) "nenhuma análise puramente funcional nos permite entender a realidade substancial do centro", ou seja, "a noção de centro da cidade tem um significado tanto espacial, histórico, funcional e sociológico" (BEAUJEU-GARNIER, apud BONNET; TOMAS, 1989, p. 3$)^{5}$.

O centro da cidade, desta maneira, não é tido neste estudo como a mesma coisa que o Distrito Central de Negócios - Central Business District (C.B.D) - tão característico das cidades dos Estados Unidos e Canadá. Este é compreendido mais como um espaço em que a funcionalidade é excessiva, um espaço de negócios por excelência, onde o prestígio se confunde com a riqueza, o poder e o espírito de competição (LABASSE, 1970). As habitações, o comércio e a rua, esta última como lugar de diversidade de atividades e do favorecimento de práticas de espaço que favorecem os contatos sensoriais, são eclipsadas pelo C.B.D (LÉVY, 1986).

Assiste-se, no contexto da urbanização contemporânea, uma disjunção entre o centro da cidade e a centralidade provocada pela localização periférica de equipamentos que tradicionalmente estavam nos centros das cidades (CHALAS, 2010). Hoje, é possível observar que com a produção de novas realidades urbanas vinculadas às atividades comerciais e de serviços distantes do centro da cidade, a centralidade foi se distanciando do centro e deixou de ser um atributo do lugar

\footnotetext{
${ }^{3}$ Tradução livre, do original: "Le centre est em fait um peu tout cela à la fois, c'est-à-dire le rassemblement des plus hautes manifestations de I avie de relations, selon le príncipe de nodalité qui est au coeur de la notion de ville. Pour le geografe, le centre est em définitive le lie ou le foyer de convergence où la ville exerce et afirme as puissance et d'où se dérage une image qui em exalte le rayonnement" (LABASSE, 1970, p. 8).

${ }^{4}$ Tradução livre, do original: "[...] aucune analyse purement fonctionnelle ne nous permet d'etreindre la réalité substantielle du centre. [...]" (LABASSE, 1970, p 14).

${ }^{5}$ Tradução livre, do original: "par J. Beaujeu- Garnier 'La notion de centre-ville a une signification à la fois spatiale, historique, fonctionnelle et sociologique"' (BONNET; TOMAS, 1989, p. 3).
} 


\section{O CENTRO DA CIDADE E AS NOVAS ÁREAS DE CENTRALIDADE NA CIDADE MÉDIA DE JUAZEIRO DO NORTE/CE}

central para ser um lugar do central $^{6}$ (leia-se, funções centrais), sem necessariamente que aquela nova área de concentração de equipamentos comerciais e de serviços da cidade seja o centro. A centralidade não é uma característica física, é "a somatória de atributos que beneficiam o Centro [mas] é importante entender que sua manifestação se dá no território da cidade de uma forma física" (TOURINHO, 2004, p. 391), ou seja, a centralidade se manifesta fisicamente no e por meio do centro ou em outras áreas com atributos semelhantes. Estas são as novas áreas de centralidade.

Antes de prosseguir, cabe uma explicação rápida no que se refere ao uso da expressão "áreas de centralidade". O argumento para o uso desta expressão é que os novos espaços que expressam centralidade no que tange ao comércio e aos serviços - hipermercados, shopping centers, etc. - são chamados inadequadamente de centros, pois a expressão centro, do ponto de vista conceitual, deveria ser resguardada para qualificar apenas o centro da cidade, pois esta área possui características que possibilitam a sua qualificação como centro. O mesmo acontece com a expressão "novas áreas centrais", visto que esta requer como condição sine qua non a existência de um centro que somado ao seu núcleo periférico, conformam a área central, como argumentaram Corrêa (1989) e Tourinho (2004). Assim, em uma cidade só existe uma área central, formada pelo seu centro e por uma área ou zona periférica. Neste sentido, nem centro nem área central são conceitos plausíveis para caracterizar estes novos espaços, o que justifica a opção de chamá-las de "centralidades sem centro", como propôs Tourinho (2004), ou poderíamos, também, chamá-los de "áreas de centralidade não-centrais" ou simplesmente áreas com expressões de centralidade.

A centralidade se caracteriza como o lugar do central (TOURINHO, 2004), o "essencial do fenômeno urbano" (LEFEBVRE, 2008, p. 108). Ela "não é outra coisa se não a aptidão da cidade a impulsionar fluxos de trocas de mercadorias, de

\footnotetext{
${ }^{6}$ Labasse (1970, apud SPOSITO, 2010, p. 203) afirma que "A centralidade nas cidades modernas deixou de identificar-se com o centro".
} 


\section{PEREIRA, C. S. S. \\ O CENTRO DA CIDADE E AS NOVAS ÁREAS DE CENTRALIDADE NA CIDADE MÉDIA DE JUAZEIRO DO NORTE/CE}

serviços e de ideias" (LABASSE, 1970, p. 11) ${ }^{7}$. É responsável pela articulação das diversas partes da cidade através dos fluxos e processos (SPOSITO, 2010a), enquanto que o centro se caracteriza como a forma espacial, em outras palavras, a "expressão territorial do processo" que é a centralidade (SPOSITO, 2010a). Também não se pode esquecer que a centralidade se manifesta de diferentes formas, melhor dizendo, com diferentes conteúdos espaciais, que podem variar, segundo Monnet (2000) entre a centralidade política, econômica, comercial, de acessibilidade, social, e a centralidade simbólica.

Ao distinguir a centralidade do centro das cidades, Castells (1988) afirma:

Este conceito [a centralidade] refere-se à combinação de vários processos sociais no espaço [econômicos, políticos, simbólicos]. Não há uma centralidade, mas um conjunto de processos que a definem. Estes processos não são necessariamente redutíveis aos centros urbanos que, eles, são entidades espaciais concretas, ligados com a história de uma cidade particular. Eles correspondem a diferentes modalidades de hierarquização urbana, de trocas na cidade e de atividade de inovação própria aos centros (CASTELLS, 1988, p. 29) (grifos nossos).

E desta maneira,

La centralidad urbana proviene, en un primer punto, de la expresión a nível de espacio de lo que los estudiosos llaman desde hace tiempo la división social del espacio. Es decir, en la medida en que hay una división del trabajo en la sociedad, en la medida en que hay distintas actividades y distintos niveles sociales ligados a estas actividades, esta división se espacializa y al espacializarse hay, a la vez, elementos de diferenciación y elementos de coordinación, tanto a nivel social como espacial. Los centros urbanos son la expresión de esta necesaria coordinación de las actividades y categorias sociales en su dimensión espacial. Es decir, los centros urbanos son la organización espacial de la puesta en relación, de intercambio, de la coordinación, con respecto al proceso de la división social del trabajo (CASTELLS, 1979, p. 230).

Muitas das novas áreas produzidas nas cidades, correntemente chamadas de "novas centralidades" - expressão que é equivocada, pois confunde a forma (o centro) com o processo (a centralidade) -, podem ser caracterizadas como

\footnotetext{
${ }^{7}$ Tradução livre, do original. "La centralité n'est pas autre chose que l'aptitude de la ville à impulser des flux d'échange de marchandises, de services et d'idées" (LABASSE, 1970, p. 11).
} 


\section{O CENTRO DA CIDADE E AS NOVAS ÁREAS DE CENTRALIDADE NA CIDADE MÉDIA DE JUAZEIRO DO NORTE/CE}

"centralidades sem centro", resultados da "desfabricação do Centro"8, visto que são simulacros espaciais, formas artificialmente criadas no espaço urbano que concentram atividades econômicas, mas que, em sentido amplo, não são centros, pois não possuem as qualidades fundamentais que caracterizam o centro. Isto é, são produzidas na cidade cada vez mais formas espaciais "que podem atuar de forma similar àqueles centros, funcionalmente falando (concentração de atividades definidas como centrais), sem, no entanto, apresentarem outros componentes de identidade do centro, como, por exemplo, os simbólicos" (TOURINHO, 2004, p. 12). Neste sentido, a afirmação de Labasse (1970) de que o centro não se reduz ao funcional, que é a característica típica do C.B.C, ajuda a sustentar a argumentação que se propõe aqui. Além disso, o que escreveu M. F. Rougue (1967, apud LABASSE, 1970, p. 13) quando afirmou que "o chamado do centro é baseado não somente no que ele oferece, mas sobre que ele representa"9 contribui a sustentar a ideia de que somente o centro principal, ou o Centro em outras palavras, pode ser caracterizado como tal.

\section{2. $\mathrm{O}$ centro da cidade e as novas áreas de centralidade em juazeiro}

\section{do norte}

Durante todo o processo de estruturação da cidade de Juazeiro do Norte ao longo do século $X X$, o centro exerceu o papel de elemento fundamental da produção da cidade, como o único espaço com expressão de centralidade. Até a década de 1980 era o centro que concentrava os principais estabelecimentos comerciais e de serviços (CEARÁ, 1980) os bancos e as lojas de eletrodomésticos. No final da

\footnotetext{
${ }^{8}$ Para Tourinho (2004, p. 336, nota 606), a "desfabricação do Centro" é um neologismo que visa identificar um desarranjo, um desconcertar, um desfazer do Centro, tirando deste "funções de comando com a finalidade de criar novas áreas representativas do novo estágio do modo de produção" que são as novas áreas de centralidade, mas que não são Centro, visto que estas "novas áreas são especializadas e quase unifuncionais: terciárias ou comerciais" diferente do Centro, que é "uma entidade multisetorial e multifuncional, plurisignificante e contraditoriamente complexa".

${ }^{9}$ Tradução livre, do original: "l'appel du centre est basé non seulement sur ce qu'il offre, mais sur ce qu'il représente" (M. F. ROUGUE, 1967, apud LABASSE, 1970, p. 13). Esta ideia é compartilhada pelo próprio Labasse (1970, p. 13), visto que como ele mesmo argumenta, o centro está no domínio do não-quantificável.
} 


\section{O CENTRO DA CIDADE E AS NOVAS ÁREAS DE CENTRALIDADE NA CIDADE MÉDIA DE JUAZEIRO DO NORTE/CE}

década de 1980 inicia-se uma desconcentração destas atividades, ainda tímida, mas que se consolidaria nos anos 1990 com a formação do subcentro Pirajá.

Atualmente, constata-se na cidade a existência de quatro áreas que concentram comércio e serviços (Figura 2): a) o centro da cidade, chamado centro principa $1^{10}$ ou de Centro; b) o Pirajá, um subcentro que surge no fim dos anos 1980; c) a área do Cariri Garden Shopping, já do final dos anos 1990; d) o Eixo JuazeiroCrato dos anos 1990 e 2000. Estas áreas se distinguem quanto à quantidade de oferta comercial e de serviços, a qualidade dos produtos, estrutura fundiária, a origem do capital dos empreendimentos, o alcance espacial ou área de influência, e o perfil dos consumidores.

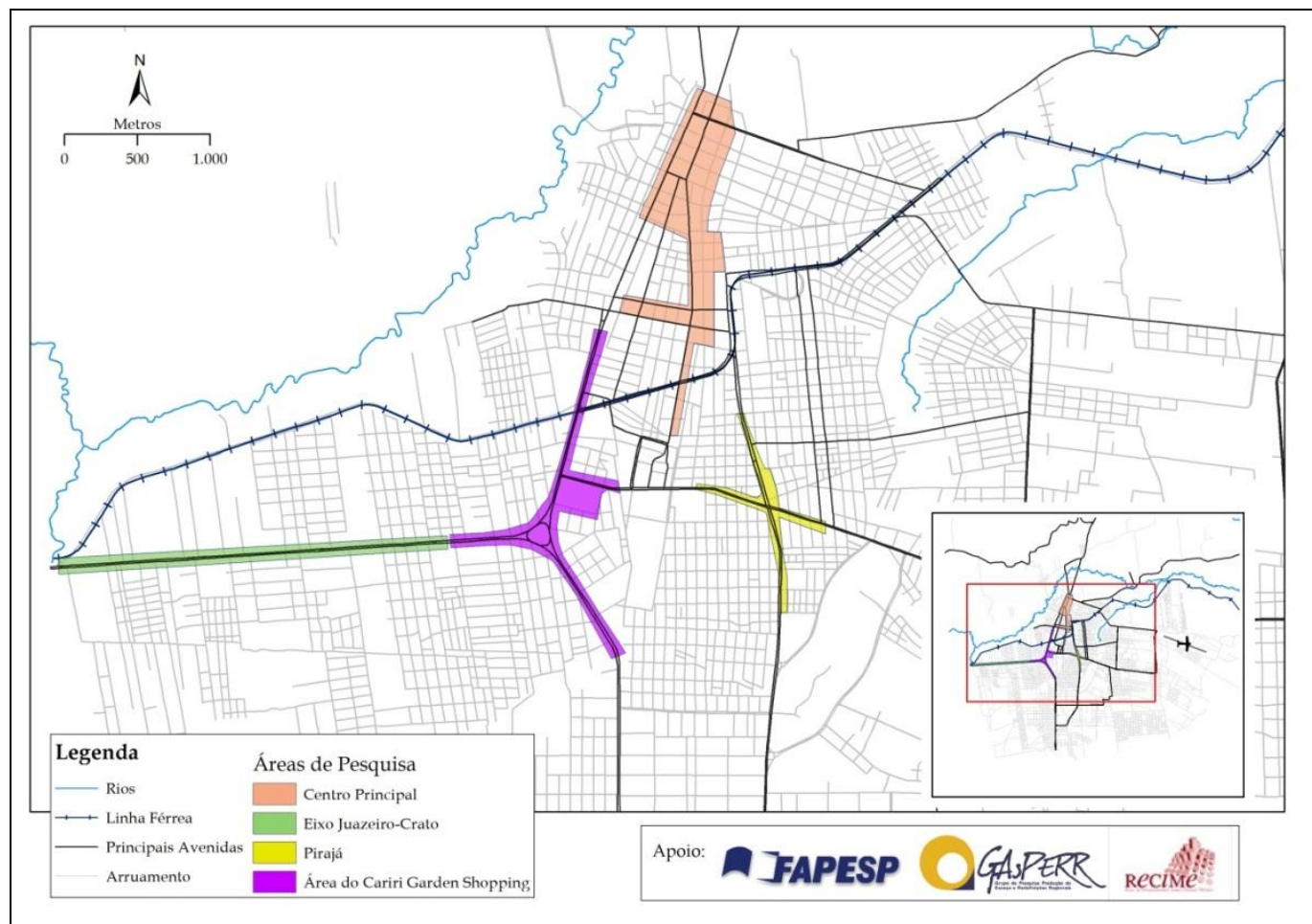

Figura 2: Juazeiro do Norte. Áreas da pesquisa de campo 2012-2013.

Fonte: Pesquisa de campo (2012-2013)

Estes espaços foram "delimitados" a partir de um levantamento de campo que buscou identificar as principais áreas da cidade que concentravam comercio e

\footnotetext{
${ }^{10} \mathrm{O}$ centro da cidade é também considerado como centro principal devido à existência do subcentro "Pirajá", e é pela articulação e comparação com este que aquele é considerado principal.
} 


\section{O CENTRO DA CIDADE E AS NOVAS ÁREAS DE CENTRALIDADE NA CIDADE MÉDIA DE JUAZEIRO DO NORTE/CE}

serviços com presença de mais de $70 \%$ destes nas ruas ou avenidas. Neste sentido, não são todas as ruas que aparecem nas áreas da figura 1 que foram levantadas, somente aquelas que apresentam um percentual de no mínimo $70 \%$ de uso do solo referente o terciário. Algumas ruas da área chamada "centro principal" não foram alvo dos levantamentos de uso do solo, ainda que possuam algumas atividades econômicas, mas de menor importância e/ou em quantidade abaixo do que caracteriza uma concentração capaz de expressar centralidade juntamente com 0 centro. No caso das demais áreas, em todas as ruas que aparecem na figura 1 foi realizado o levantamento de campo, visto que, diferentemente do centro principal, os estabelecimentos comerciais e de serviços aparecem concentrados em poucas ruas ou avenidas.

Quando se observa o total dos estabelecimentos que foram levantados e os que estão funcionando, conforme tabela 1, pode-se perceber a nítida preponderância do centro da cidade em relação às demais áreas de centralidade.

Tabela 1: Juazeiro do Norte. Quantidade de estabelecimentos levantados e em funcionamento nas áreas de centralidade*. 2012-2013.

\begin{tabular}{lcccc}
\hline & $\begin{array}{c}\text { Quant. de } \\
\text { estabelecimentos em } \\
\text { funcionamento }\end{array}$ & $\%$ & $\begin{array}{c}\text { Quant. de } \\
\text { estabelecimentos } \\
\text { levantados }\end{array}$ & $\%$ \\
\hline Centro Principal & 1796 & 71,43 & 2630 & 71,77 \\
Pirajá & 435 & 17,30 & 701 & 19,13 \\
Cariri Shopping & 181 & 7,19 & 207 & 5,64 \\
$\begin{array}{l}\text { Eixo Juazeiro- } \\
\text { Crato }\end{array}$ & 102 & 4,05 & 126 & 3,43 \\
\hline Total & 2514 & 100 & 3664 & 100 \\
$*$ & Por ocasião do levantamento não foi feita uma separação entre atacadistas e varejistas \\
Fonte: Pesquisa de campo (2012-2013).
\end{tabular}

No caso de Juazeiro do Norte, somente o Pirajá, pela sua similaridade com o centro da cidade no que tange à formação e as iniciativas individuais dos comerciantes entre outras características ${ }^{11}$, é chamado de subcentro, justamente porque tem uma expressão territorial menor e uma diversificação comercial reduzida em relação ao centro da cidade, mesmo sendo semelhante àquele no contexto do

\footnotetext{
${ }^{11}$ Sobre as características similares entre o centro e os subcentros ver Sposito (2013).
} 


\section{O CENTRO DA CIDADE E AS NOVAS ÁREAS DE CENTRALIDADE NA CIDADE MÉDIA DE JUAZEIRO DO NORTE/CE}

processo histórico de sua produção. As "centralidades sem centro", no caso de Juazeiro do Norte, seriam as áreas do Cariri Garden Shopping e o Eixo JuazeiroCrato, cujo papel deriva em grande parte de iniciativas de agentes econômicos de capital nacional e internacional em grandes superfícies comerciais que expressam centralidade para toda a cidade.

$\mathrm{Na}$ pesquisa foram selecionados três ramos de atividades que são significativos para se pensar a centralidade na cidade de Juazeiro do Norte. No âmbito da atividade comercial, foram selecionadas as lojas de eletrodomésticos e os super e hipermercados, associados ou não a shopping centers, pois estas atividades apresentavam, a primeira mais timidamente que a segunda, uma localização significativa fora do centro da cidade. Já pelos serviços, as atividades bancárias foram escolhidas porque também permitem uma leitura do processo de redefinição da centralidade urbana na cidade estudada.

Com os levantamentos de campo e as consultas em alguns sites específicos - como o do Banco Central do Brasil (BACEN) - montou-se a tabela 2, que apresenta a quantidade de estabelecimentos nas áreas estudadas divididas por setor.

Tabela 2: Juazeiro do Norte. Distribuição dos estabelecimentos selecionados por área da pesquisa em números absolutos. 2012-2013

\begin{tabular}{lcccc}
\hline & \multicolumn{5}{c}{ Estabelecimentos } \\
\hline Bancos & PAEs/PABs* & Eletrodomésticos & $\begin{array}{c}\text { Super e } \\
\text { Hipermercados }\end{array}$ \\
\hline Centro Principal & 8 & 5 & 26 & 2 \\
Área & 2 & 3 & 6 & 1 \\
Garden Shopping & 2 & 8 & 3 & 1 \\
Eixo Juazeiro-Crato & 0 & 2 & 2 & 3 \\
\hline \multicolumn{1}{c}{ Total } & 12 & 18 & 37 & 7 \\
\hline
\end{tabular}

* Postos de Atendimento Eletrônico (PAE) e Postos de Atendimento Bancário (PAB)

Fonte: Pesquisa de campo (2012-2013)

As atividades bancárias se concentram, do ponto de vista espacial, de maneira nítida no centro da cidade, com 8 estabelecimentos, enquanto que nas outras áreas, apenas dois no Pirajá e dois na área do Cariri Garden Shopping. 


\section{O CENTRO DA CIDADE E AS NOVAS ÁREAS DE CENTRALIDADE NA CIDADE MÉDIA DE JUAZEIRO DO NORTE/CE}

Entretanto, o que chama atenção quanto a isso é mais o processo do que a localização, pois se observa uma desconcentração da atividade bancária nos últimos anos, visto que as novas agências que se instalaram na cidade buscaram outros espaços que não o centro da cidade (fotos 1 e 2 )

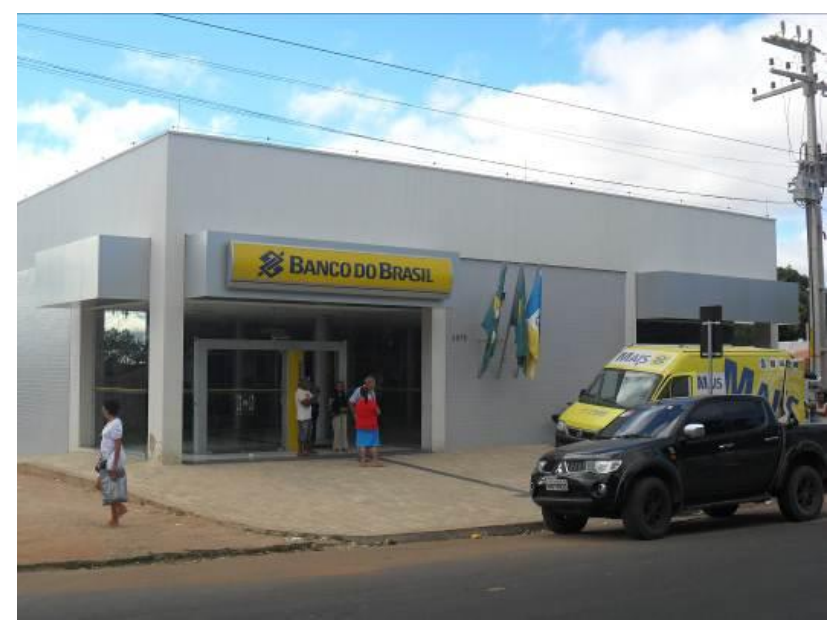

Foto 1: Juazeiro do Norte. Agência do Banco do Brasil do Pirajá.

Fonte: Pesquisa de campo (2012-2013).

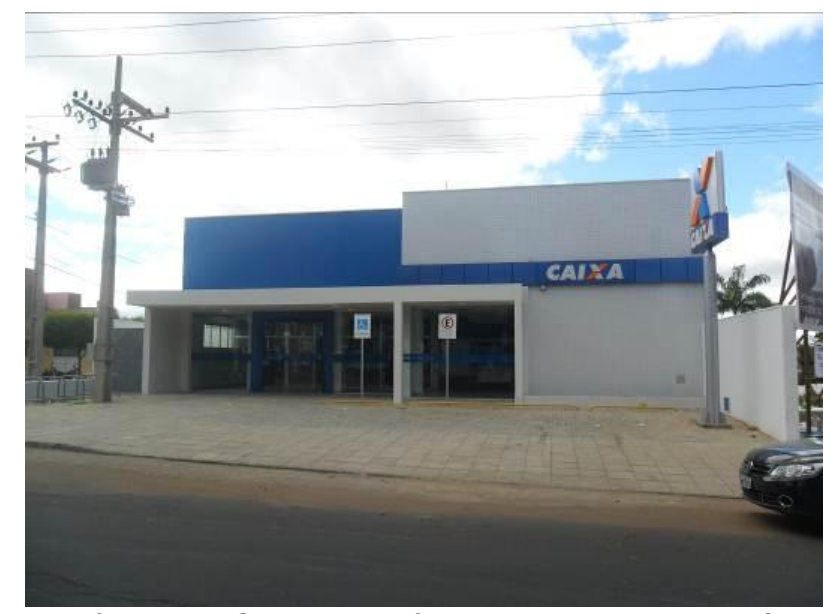

Foto 2: Juazeiro do Norte. Agência da Caixa Econômica Federal do Pirajá.

Fonte: Pesquisa de campo (2012-2013).

Os Postos de Autoatendimento Bancário (PAB) e os Postos de Autoatendimento Eletrônico (PAE) tiveram uma desconcentração mais intensa, visto que o seu número ampliou nos últimos anos e as suas estratégias de localização se basearam em não mais ter o centro da cidade como único espaço para tais serviços. 


\section{O CENTRO DA CIDADE E AS NOVAS ÁREAS DE CENTRALIDADE NA CIDADE MÉDIA DE JUAZEIRO DO NORTE/CE}

O gráfico 1 apresenta o processo de desconcentração destas atividades a partir do ano de $2007^{12}$.

Pode-se visualizar que pelo lado das agências bancárias, o centro da cidade praticamente não se "desenvolveu", recebendo apenas uma agência nos últimos sete anos, ao contrário do Pirajá e da Área do Cariri Garden Shopping (no gráfico ambas constam como "fora do centro") que receberam cada uma duas agências, a primeira área em 2011 e 2012, e a última área em 1999 e 2013, respectivamente.

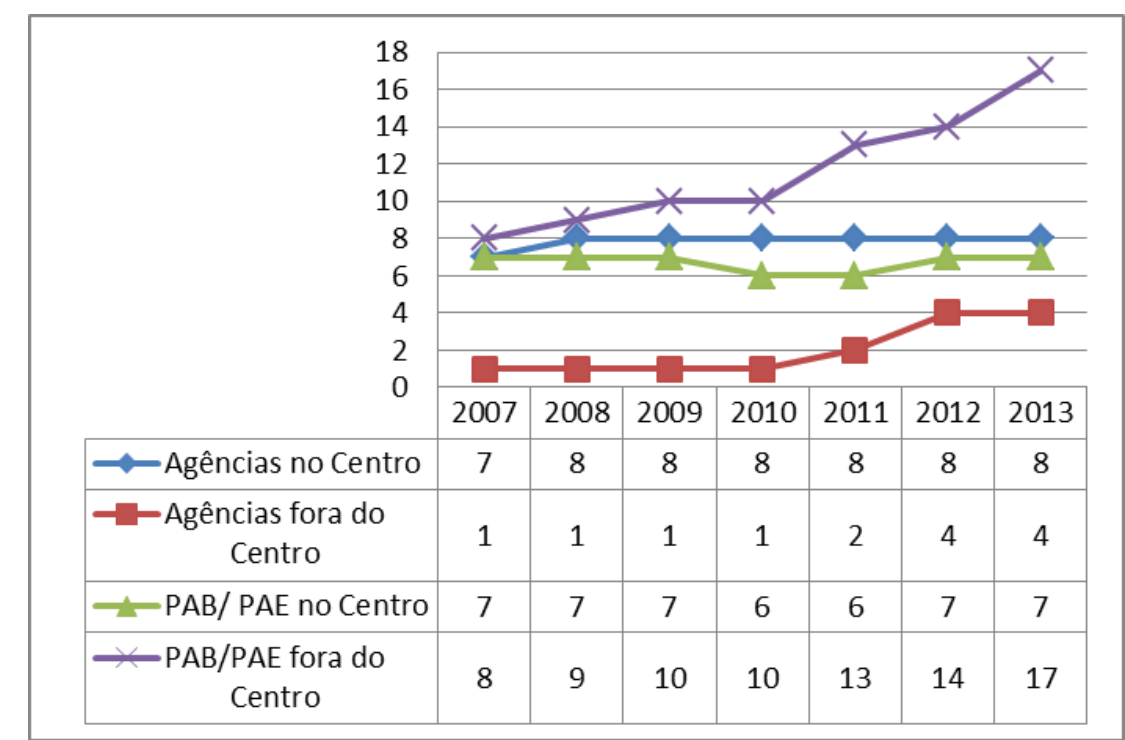

Gráfico 1: Juazeiro do Norte. Evolução das agências bancárias e PABs e PAESs no centro e fora do centro da cidade. 2007 a 2013

Fonte: BACEN - Banco Central do Brasil (2013).

Como as demais atividades comerciais e de serviços, os bancos e as atividades financeiras também precisam de estratégias de localização para poder funcionar, estratégias estas que se baseiam em economias de aglomeração por

\footnotetext{
${ }^{12} \mathrm{O}$ ano inicial é 2007 porque as informações disponíveis no site do Banco Central são a partir deste ano.
} 


\section{PEREIRA, C. S. S. \\ O CENTRO DA CIDADE E AS NOVAS ÁREAS DE CENTRALIDADE NA CIDADE MÉDIA DE JUAZEIRO DO NORTE/CE}

meio da concentração espacial ${ }^{13}$. No âmbito do espaço urbano - e da rede urbana também - os bancos não se distribuem de forma homogênea, mas sim de forma seletiva, naquilo que Garrocho-Rangel e Campos-Alanís (2010) chamam de "sítios estratégicos". Estes sítios estratégicos se referem a espaços na cidade que facilitam a realização das atividades financeiras, isto é, maximizam a acessibilidade ao cliente, as vendas de serviços bancários e as ganâncias da firma (GARROCHORANGEL; CAMPOS-ALANÍS, 2010), e são exemplificados a partir de pelo menos quatro exemplos:

[...] lo atractivo del sitio (una plaza comercial de lujo es más atractiva que un barrio marginal), los costos de transporte (usualmente el centro de la ciudad - los subcentros de actividad son más accesibles que las zonas periféricas), la calidad de las vialidades (una gran avenida ofrece más ventajas de ubicación y visibilidad que una calle secundaria) o las percepciones diferenciadas de los clientes (la apreciación de la seguridad en ciertas zonas de la ciudad o lo atractivo que le resultan ciertos espacios intraurbanos a cada segmento del mercado) (GARROCHO-RANGEL; CAMPOS-ANALÍS, 2010, p. 417).

Desse modo, o centro principal de Juazeiro do Norte parece ser o "sítio estratégico" privilegiado para a localização dos bancos, e pelo menos vinha sendo até o final dos anos 1990, quando outras áreas passaram a ser atraentes para o setor bancário relacionado a novas tendências de produção do espaço urbano e a segmentação social. Espacializando esta atividade, o resultado é o que está exposto na figura 3, com as agências, os PABs e os PAEs localizados de acordo com as áreas de centralidade no espaço urbano.

\footnotetext{
13 “[...] la mayoría de las firmas comerciales y de servicios (como las sucursales bancarias) ofrecen una mezcla de productos que son sustitutos imperfectos y complementarios,y por tanto se organizan espacialmente en forma de clusters para facilitar y hacer más económico al consumidor su proceso de búsqueda y compra de productos, así como aprovechar otras importantes economías de aglomeración, como se explica" (GARROCHO-RAGEL; CAMPOS-ANALíS, 2010, p. 419).
} 


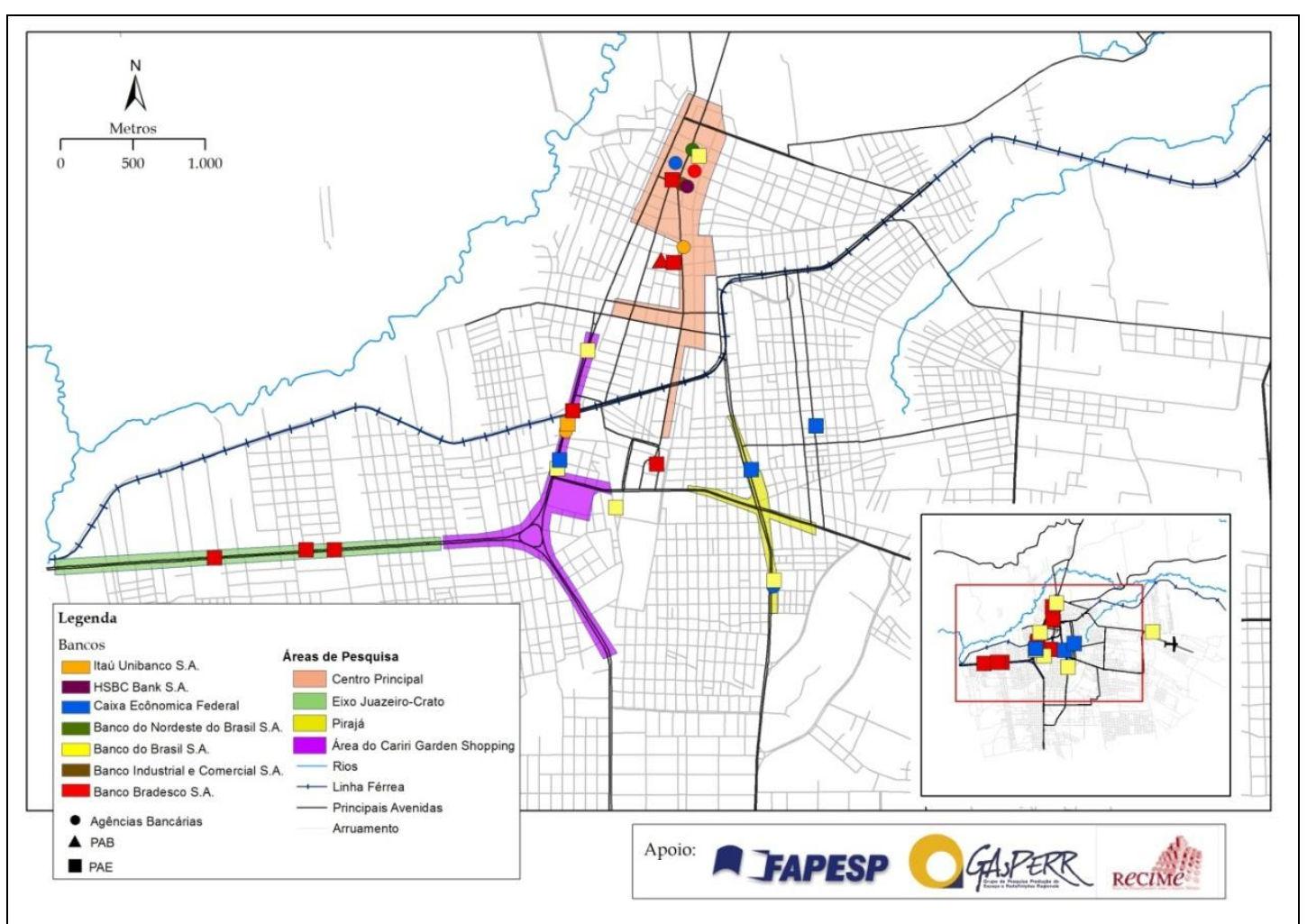

Figura 3: Juazeiro do Norte. Distribuição espacial das agências, PAEs e PABs. 2012-2013.

Fonte: Pesquisa de Campo (2012-2013).

Já no caso dos estabelecimentos de eletrodomésticos, a diferença entre o centro da cidade e as demais áreas é também significativa. $O$ centro da cidade concentra 26 das 37 lojas, o que corresponde a $70 \%$ do total de estabelecimentos deste ramo de atividade. As demais áreas, do ponto de vista da quantidade de estabelecimentos, são: o Pirajá com seis, a área do Cariri Garden Shopping com três e o Eixo Juazeiro-Crato com duas.

No centro principal, a Rua São Pedro se destaca com 20 estabelecimentos de eletrodomésticos de um total de 26 , o que representa $76 \%$ do montante geral, conforme apresentado na figura 4 . As demais ruas que tem presença de lojas deste ramo são a Rua Santa Luzia com três e as ruas São Francisco, São Paulo e do Cruzeiro, cada uma com um estabelecimento (tabela 3). 


\section{O CENTRO DA CIDADE E AS NOVAS ÁREAS DE CENTRALIDADE NA CIDADE MÉDIA DE JUAZEIRO DO NORTE/CE}

Tabela 3: Juazeiro do Norte. Distribuição dos estabelecimentos de eletrodomésticos nas ruas do centro principal.

\begin{tabular}{|c|c|c|c|}
\hline Ruas & Quantidade & $\%$ & Nome do estabelecimento \\
\hline Rua São Pedro & 20 & 76 & $\begin{array}{l}\text { Top Moveis }(2)^{\star} \text {, Rabelo }(3) \text {, Macavi, Zenir, } \\
\text { Eletroshopping, Dulare (2) Lojas Maia/Magazine } \\
\text { Luiza (2), Casas Bahia, Vip Shop, Casas Mauris, } \\
\text { Max Móveis, Shop Móveis, Eletrosul, Magazine } \\
\text { Eletrosul, Som \& Cia }\end{array}$ \\
\hline Rua Santa Luzia & 3 & 12 & Max Móveis, Insinuante, Rabelo \\
\hline Rua São Paulo & 1 & 4 & Eletrocariri \\
\hline $\begin{array}{ll}\text { Rua } & \text { São } \\
\text { Francisco } & \end{array}$ & 1 & 4 & Liliani \\
\hline Rua do Cruzeiro & 1 & 4 & Lojas Americanas \\
\hline Total & 26 & 100 & - \\
\hline
\end{tabular}

Observação: quase todas as lojas comercializam móveis juntamente com os eletrodomésticos.

* O número entre parêntese significa a quantidade de unidades da mesma loja

Fonte: Pesquisa de campo (2012-2013)

As principais lojas deste ramo pertencem a redes que se organizam e atuam em escalas espaciais mais amplas, não se restringindo apenas à cidade de Juazeiro do Norte, e, além disto, são de capitais extra-locais, os quais serão denominados de: a) capital local-regional - para se referir a lojas como a Zenir Móveis e Eletrodomésticos, a Macavi e a Rabelo, que são lojas de capital cearense; b) capital regional - de origem além das fronteiras cearenses, mas que são nordestinas, no caso da Liliane; c) capital nacional - presentes na escala do Brasil, como a Insinuante, a Magazine Luiza e a Casas Bahia (fotos 3 e 4).
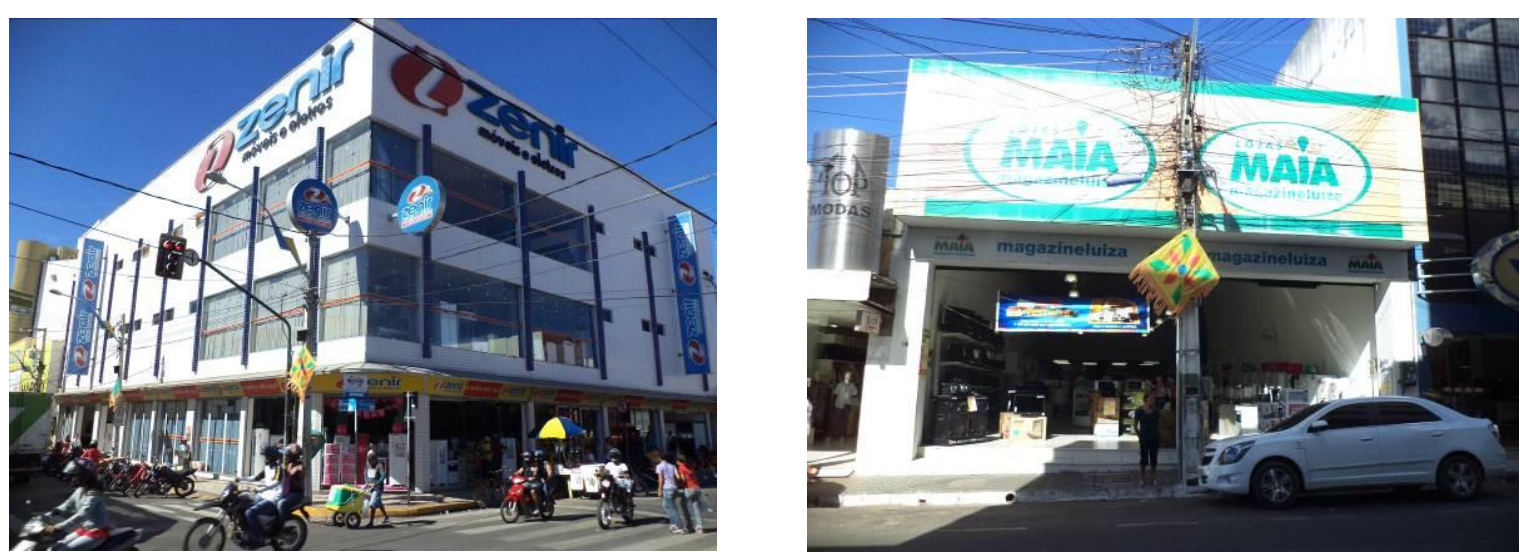

Fotos 3 e 4: Juazeiro do Norte. A esquerda a Zenir Móveis e Eletro do centro principal, e a direita uma das Lojas Maia/Magazine Luiza do centro principal.

Fonte: Pesquisa de Campo 2012-2013 
PEREIRA, C. S. S.

O CENTRO DA CIDADE E AS NOVAS ÁREAS DE CENTRALIDADE NA CIDADE MÉDIA DE JUAZEIRO DO NORTE/CE

As lojas de eletrodomésticos diferenciam-se, destarte, conforme a origem do capital. No centro principal, existe uma diversificação das empresas, desse ponto de vista. A presença maior são as de capital local (próprias da cidade), local-regional (lojas cearenses) e regional (nordestinas). As de capital nacional, que estão presentes naquela área são as Lojas Americanas, a Insinuante, a Casas Bahia e a Lojas Maia/Magazine Luiza ${ }^{14}$. No Pirajá, as lojas deste ramo são todas de origem do capital local, sendo que algumas são de novos e usados, realizando não só vendas, mas trocas também. Já no Cariri Garden Shopping, são a Magazine Luiza e as Lojas Americanas ${ }^{15}$, de capital nacional, que se destacam, enquanto que, no Eixo Juazeiro-Crato, as duas lojas existentes são de capital local-regional, a Zenir e a Macavi, como se observa na figura 4 e nas fotos 5 e 6 .
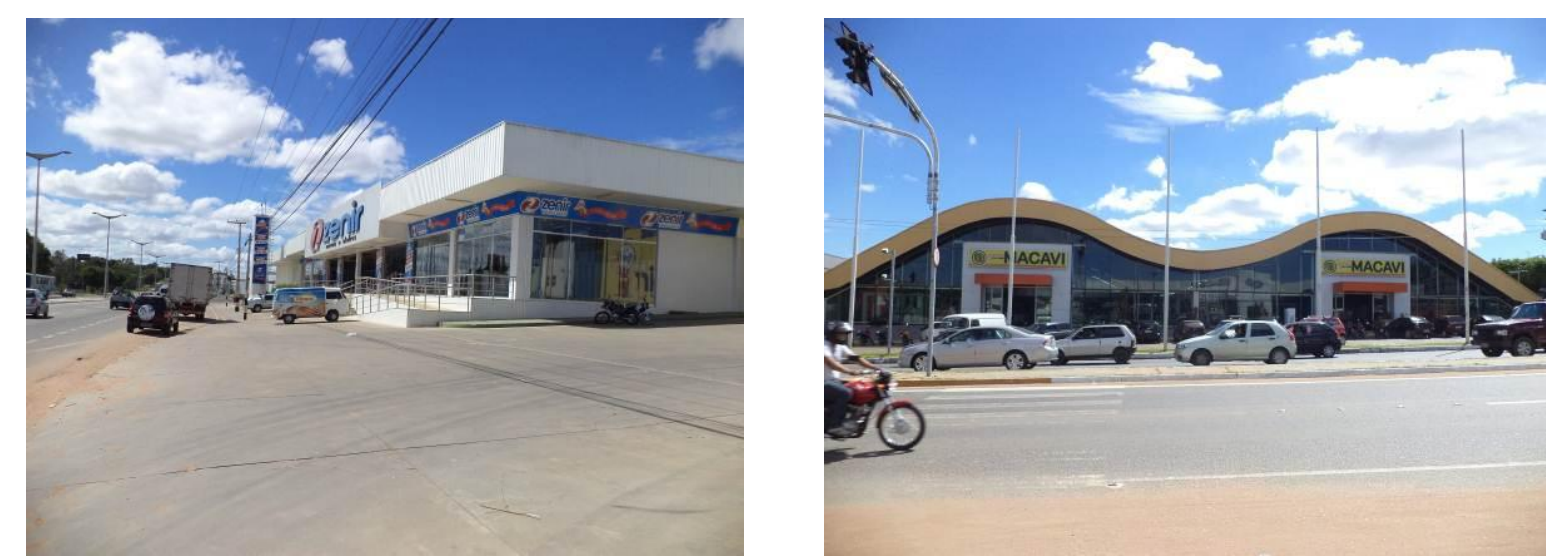

Fotos 5 e 6 - Juazeiro do Norte. Zenir Móveis e Eletrodomésticos e Macavi, avenida Padre Cicero, Eixo Juazeiro-Crato

Fonte: Pesquisa de Campo 2012-2013

\footnotetext{
${ }^{14}$ A Insinuante uniu-se com a Ricardo Eletro e formou a Máquina de Vendas, podendo, assim, ser classificada como nacional.

${ }^{15}$ As Lojas Americanas são classificadas no ramo de eletrodomésticos segundo o ranking da IBEVAR, disponível em <http://www.esperienza.com.br/ibevar/f01/pdf/pesquisa-epublicacoes/ranking-ibevar-novo-indd-2012.pdf>. Acesso em: 31 ago. 2013.
} 


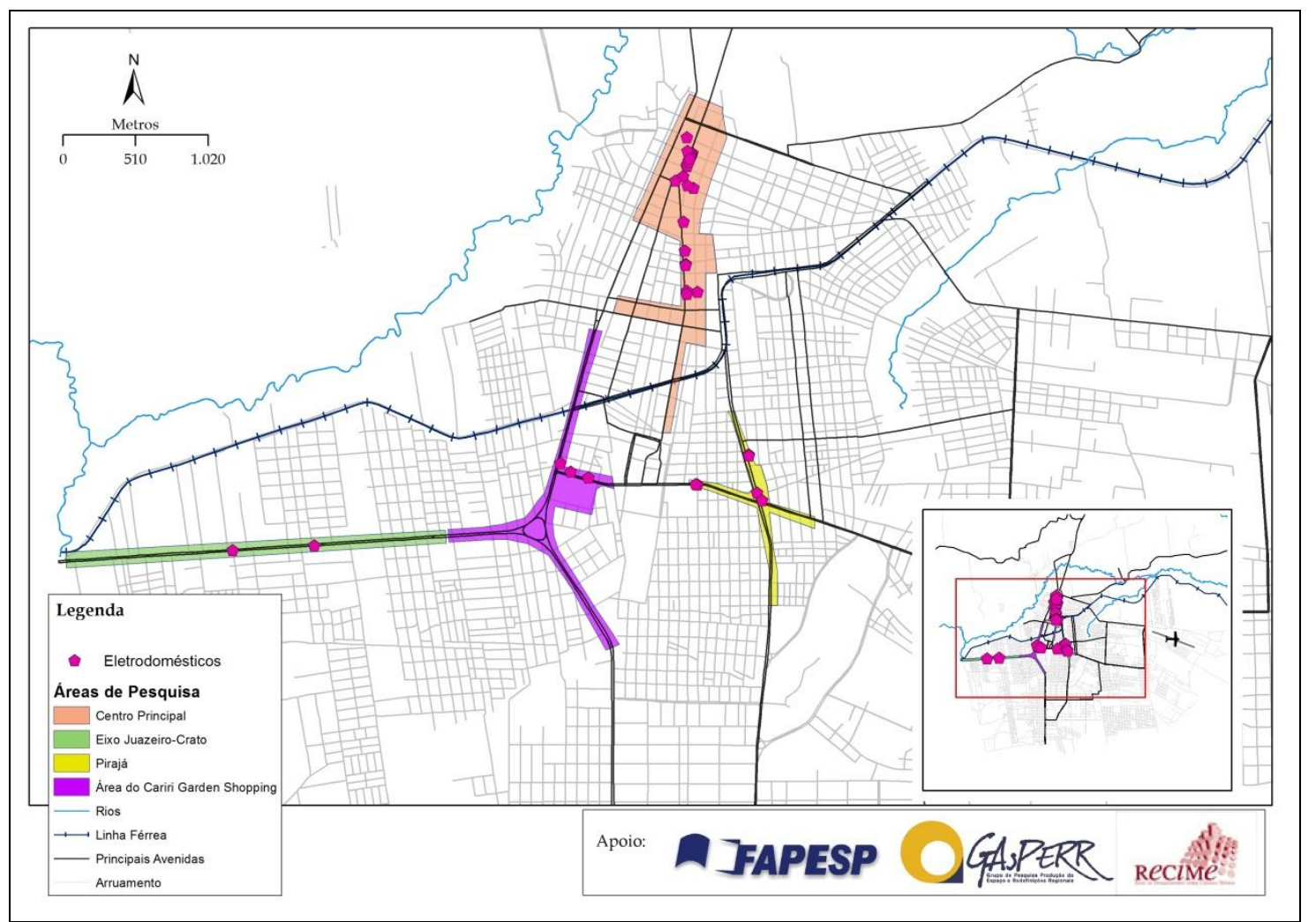

Figura 4 - Juazeiro do Norte. Distribuição espacial das lojas de eletrodomésticos Fonte: Pesquisa de Campo (2012-2013).

As novas lógicas de localização periférica de estabelecimentos comerciais e de serviços que têm influenciado a recente estruturação das cidades brasileiras interferem igualmente no comércio que se encontra tradicionalmente no centro principal da cidade, como o de venda de eletrodomésticos. Como afirmou Sposito (2010a, p.212), "as novas localizações periféricas acentuam a composição de um mosaico que caracteriza a estruturação recente das cidades, especialmente no Brasil”. Em Juazeiro do Norte isso se manifesta de maneira interessante, visto que as lojas de eletrodomésticos que estão mais distante do centro principal são de capital local-regional.

Todavia, a atividade econômica que mais tem chamado atenção no que concerne a produção de novas áreas de centralidade em Juazeiro do Norte tem sido as referentes ao setor comercial varejista e atacadista de grande porte. São estas 


\title{
O CENTRO DA CIDADE E AS NOVAS ÁREAS DE CENTRALIDADE NA CIDADE MÉDIA DE JUAZEIRO DO NORTE/CE
}

empresas de capital nacional e internacional - shopping centers ${ }^{16}$, super e hipermercados - que passaram a operar em muitas cidades médias e de porte médio do Brasil. Para se ter uma ideia, em Juazeiro do Norte, o montante investido nestes ramos desde de 2009 chega a $\mathrm{R} \$ 260$ milhões.

De modo geral, as novas formas comerciais se ampliaram no Brasil a partir dos anos 1980, com o surgimento e ampliação de shopping centers, hipermercados, galerias, no momento em que se deu um processo significativo de concentração econômica em alguns ramos comerciais, acentuando-se nos anos 1990 com o crescimento da presença de agentes econômicos de capitais internacionais ligados ao autosserviço (SPOSITO, 2010a).

Essas empresas utilizam-se de diversas estratégias para produzirem novos espaços de concentração de atividades econômicas no espaço urbano. Sobre esse assunto, Sposito (2010a) observa que

\begin{abstract}
[...] as redes de distribuição comercial e de serviços, ao instalarem esses grandes equipamentos [os shopping centers, os super e hipermercados], não somente respondem aos interesses das novas zonas residenciais e aos hábitos de uso cada vez mais frequentes do automóvel, mas, sobretudo, propõem e criam uma nova [área] centralidade. Para fazê-lo, incluem no projeto imobiliário e na estratégia locacional elementos capazes de materializar objetivamente essa centralidade (acesso ao sistema de circulação, vastas áreas de estacionamento, oferta concentrada de produtos e serviços etc.) e de maneira subjetiva (nova imagem urbana, marca do modernismo etc.) (SPOSITO, 2010a, p.207).
\end{abstract}

As empresas de capital nacional e internacional destacam-se quanto ao seu papel no processo de estruturação recente de Juazeiro do Norte. Instaladas quase todas em uma mesma via - a Avenida Padre Cícero (Eixo Juazeiro-Crato) transformaram a área em vetor de expansão urbana e de valorização do solo urbano (Figura 5). A inauguração do Assaí em 2013 de frente ao Atacadão, acirrando a concorrência das grandes redes varejistas, apenas confirma a tendência de

\footnotetext{
${ }^{16} \mathrm{O}$ atual Cariri Garden Shopping se chamava Cariri Shopping até 2009, e mudou de nome após a empresa Tenco Shopping Centers compra-lo do BicBanco, em 2008, por R $\$ 70$ milhões (NETZ, 2010).
} 


\section{O CENTRO DA CIDADE E AS NOVAS ÁREAS DE CENTRALIDADE NA CIDADE MÉDIA DE JUAZEIRO DO NORTE/CE}

estratégia na localização ${ }^{17}$ destas atividades baseadas no mercado consumidor crescente.

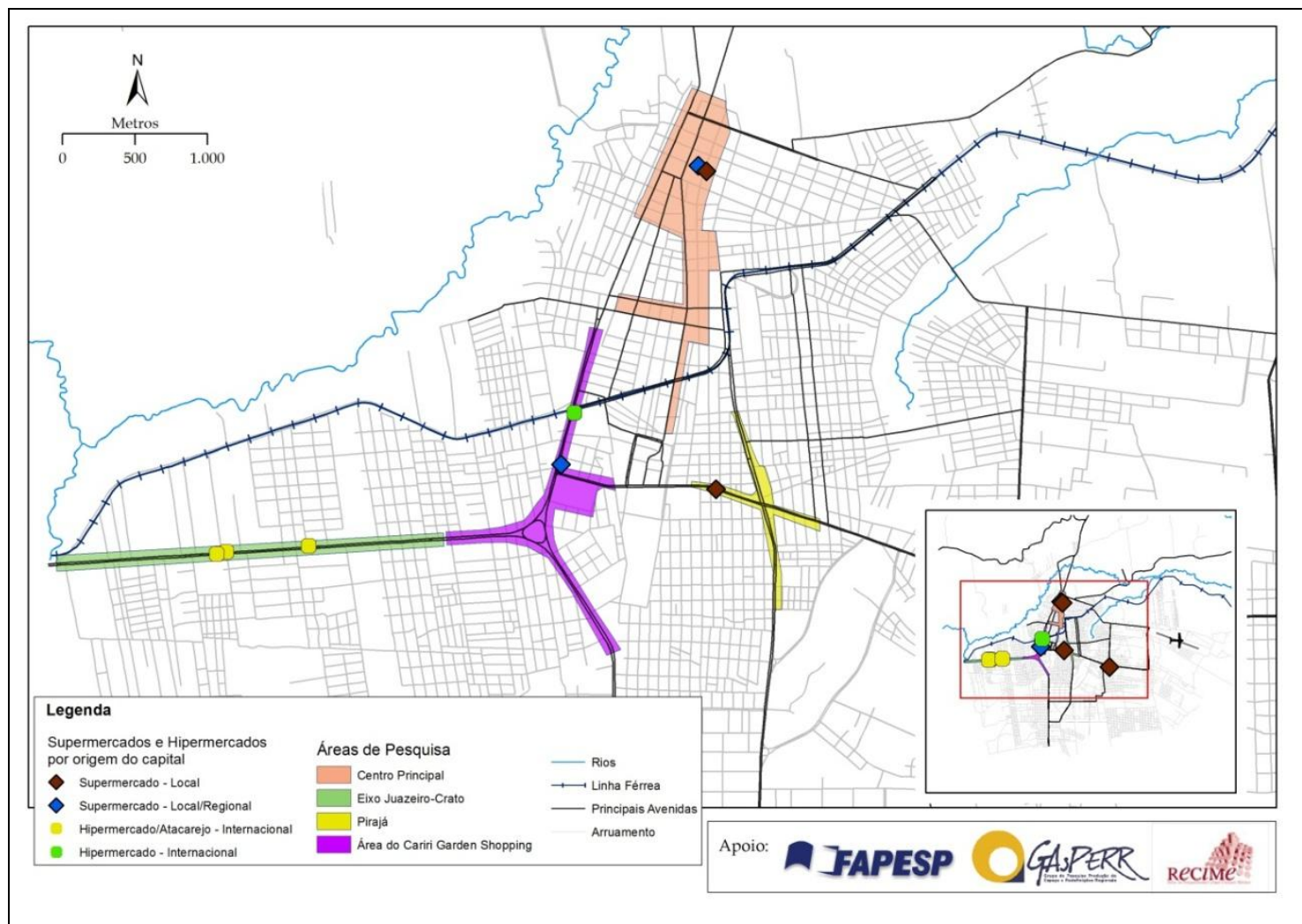

Figura 5: Juazeiro do Norte. Localização dos principais supermercados e hipermercados segundo origem de capital.

Fonte: Pesquisa de Campo (2012-2013).

No caso dos super e hipermercados (quadro 1 e fotos 7 e 8) o impacto foi grande. Segundo Aníbal Feijó, presidente da Associação Cearense de Supermercados (ACESU), a inauguração do Atacadão em 2009 - que foi construído em apenas 86 dias - impactou de forma negativa as lojas do mesmo ramo na cidade, com uma redução de $30 \%$ no faturamento (ANCHIETA, 2010). Não só no âmbito do faturamento, mas, sobretudo, no processo de estruturação da cidade,

\footnotetext{
17 Vargas (1995) faz uma diferença entre "localização estratégica" e "estratégia da localização". A primeira refere-se à localização como sendo o aspecto fundamental para a tomada de decisões das atividades terciárias; já a segunda refere-se ao poder que os novos espaços de consumo (shopping centers, hipermercados etc.) tem na produção de localizações.
} 


\section{O CENTRO DA CIDADE E AS NOVAS ÁREAS DE CENTRALIDADE NA CIDADE MÉDIA DE JUAZEIRO DO NORTE/CE}

esses empreendimentos são significativos por produzirem uma cidade cada vez mais estendida e, em alguns casos, descontínua do ponto de vista territorial.

\begin{tabular}{|c|c|c|c|c|}
\hline Empresa & Tipo & $\begin{array}{c}\text { Origem do } \\
\text { Capital }\end{array}$ & Área da Pesquisa & Bairro \\
\hline Assaí & $\begin{array}{l}\text { Hipermercado - } \\
\text { Atacarejo }\end{array}$ & Internacional & Eixo Juazeiro-Crato & São Jose \\
\hline Atacadão & $\begin{array}{l}\text { Hipermercado - } \\
\text { Atacarejo }\end{array}$ & Internacional & Eixo Juazeiro-Crato & São Jose \\
\hline Maxxi & $\begin{array}{l}\text { Hipermercado - } \\
\text { Atacarejo }\end{array}$ & Internacional & Eixo Juazeiro-Crato & São Jose \\
\hline Hiper Bompreço & Hipermercado & Internacional & $\begin{array}{l}\text { Cariri Garden } \\
\text { Shopping }\end{array}$ & Triangulo \\
\hline Super Yohanne & Supermercado & Local & Centro Principal & Centro \\
\hline $\begin{array}{l}\text { Supermercado } \\
\text { Nogueira }\end{array}$ & Supermercado & Local & Juazeiro Shopping & Tiradentes \\
\hline $\begin{array}{l}\text { Supermercado } \\
\text { Econômico }\end{array}$ & Supermercado & Local & Pirajá & Pirajá \\
\hline $\begin{array}{l}\text { Mercadinho São } \\
\text { Luiz }\end{array}$ & Supermercado & Local/ regional & $\begin{array}{l}\text { Cariri Garden } \\
\text { Shopping }\end{array}$ & Triangulo \\
\hline Super Lagoa & Supermercado & Local/ regional & Centro Principal & Centro \\
\hline
\end{tabular}

Quadro 1: Juazeiro do Norte. Distribuição espacial das grandes superfícies comerciais varejistas e atacadistas. 2013.

Fonte. Pesquisa de campo (2012-2013).

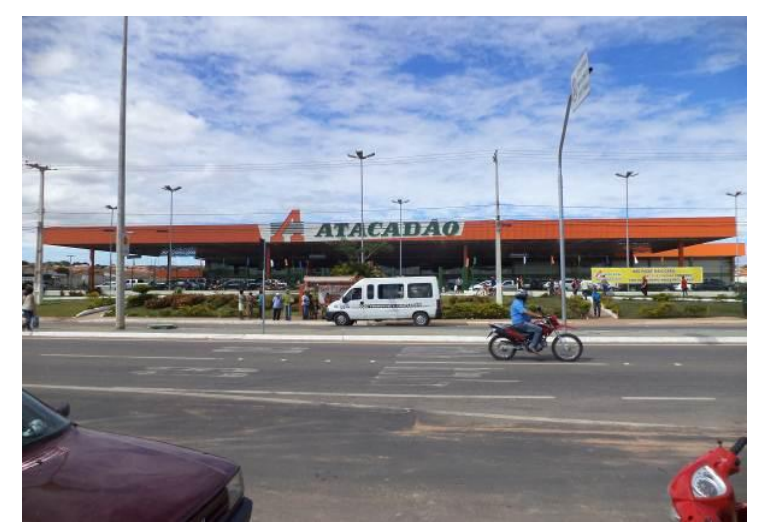

Foto 7: Juazeiro do Norte. Atacadão, do Grupo Carrefour, na Av. Padre Cícero.

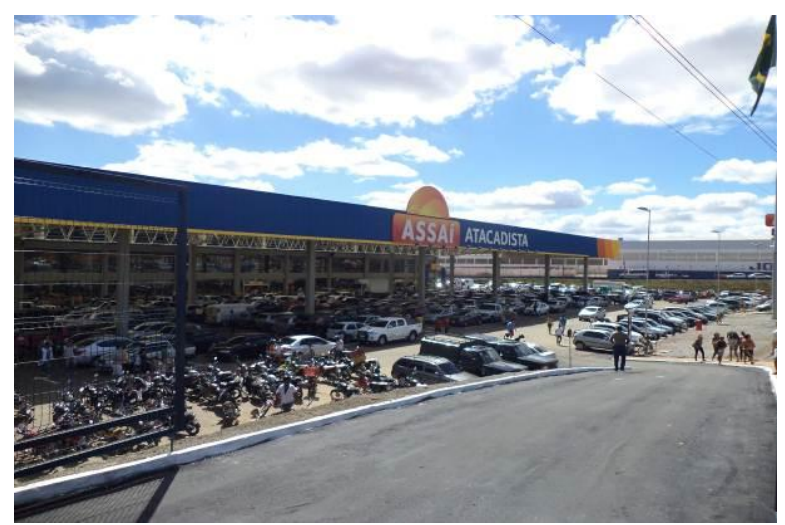

Foto 8: Juazeiro do Norte. Assaí Atacadista, do Grupo Pão de Açúcar, na Av. Padre Cícero.

Como bem apontou Baudrillard (1991), o hipermercado é inseparável das autoestradas, dos parques de estacionamento para os automóveis; é um núcleo e estabelece uma órbita sobre qual se move a aglomeração e, por isso, desintegra a própria cidade. O hipermercado seria, para o autor, um modelo hiper-real que não tem nada a ver com a cidade, esta, que junto com o campo, desapareceriam para 


\section{PEREIRA, C. S. S. \\ O CENTRO DA CIDADE E AS NOVAS ÁREAS DE CENTRALIDADE NA CIDADE MÉDIA DE JUAZEIRO DO NORTE/CE}

formar a aglomeração urbana funcional e sinalizada, produtora de uma nova sociabilidade. O hipermercado $\mathrm{e}$ as demais grandes superfícies comerciais acabaram "negando a rua como espaço de diálogo" (SALGUEIRO, 1996, p. 232).

$O$ faturamento deste tipo de comércio na cidade de Juazeiro do Norte é significativo. $O$ caso do Atacadão é exemplar, pois o seu faturamento chega a $R \$ 18$ milhões por mês (SERPA, 2013) o que demonstra a força do mercado varejista nesta cidade. Além disso, ressalta-se que todos os empreendimentos de capital internacional que são líderes de faturamento do setor supermercadista encontram-se em Juazeiro do Norte, conforme tabela 4, e ocupam grandes áreas com um amplo e diversificado mix de produtos além de estacionamentos com capacidade para centenas de veículos, conforme dados contidos na tabela 5 .

Tabela 4: Brasil. Maiores redes supermercadistas. 2011.

\begin{tabular}{ccccc}
\hline Posição & Grupo & Origem do Capital & $\begin{array}{c}\text { Faturamento (em } \\
\mathbf{R \$} \text { Bilhões) }\end{array}$ & $\begin{array}{c}\text { Fatia de mercado } \\
(\mathbf{e m ~ \% )})^{\star \star}\end{array}$ \\
\hline 1 & Pão de Açúcar & França-Brasil & 28,93 & 12,8 \\
2 & Carrefour & França & 28,76 & 12,7 \\
3 & Wal-Mart & Estados Unidos & 23,46 & 10,4 \\
4 & Cencosud & Chile & 8,89 & 3,9 \\
\hline Total & - & - & 90,04 & 39,8 \\
\hline
\end{tabular}

* Controle Acionário do Grupo francês Casino; ** Números aproximados

Fonte: Sousa (2013).

Tabela 5: Juazeiro do Norte. Especificações dos estabelecimentos do setor supermercadista. 2013

\begin{tabular}{|c|c|c|c|c|c|c|c|c|}
\hline & $\begin{array}{c}\text { Área } \\
\text { total } \\
\left(\mathrm{mil} \mathrm{m}^{2}\right)\end{array}$ & $\begin{array}{c}\text { Área } \\
\text { construída } \\
\left(\mathrm{m}^{2}\right)\end{array}$ & $\begin{array}{l}\text { Área da } \\
\text { loja }\left(\mathrm{m}^{2}\right)\end{array}$ & $\begin{array}{l}\text { Check- } \\
\text { outs }\end{array}$ & Mix & $\begin{array}{c}\text { Vagas } \\
\text { Estacio- } \\
\text { namento }\end{array}$ & $\begin{array}{c}\text { Investimento } \\
\text { (em R\$ } \\
\text { milhões) }\end{array}$ & $\begin{array}{c}\text { Ano de } \\
\text { Inaugu- } \\
\text { ração }\end{array}$ \\
\hline Atacadão & 30 & 16.635 & 6.300 & 30 & 10.000 & 532 & 30 & 2009 \\
\hline $\begin{array}{l}\text { Hiper } \\
\text { Bompreço }\end{array}$ & 22,4 & 7.500 & 3.600 & 25 & 45.000 & 306 & 35 & 2011 \\
\hline Maxxi & 20 & - & 4.900 & 16 & 6.000 & 228 & 30 & 2012 \\
\hline Assaí & 27 & 13.703 & 5.700 & 26 & 6.000 & 349 & 35 & 2013 \\
\hline Total & 99,4 & 37.838 & 20.500 & 97 & 67.000 & 1.415 & 130 & - \\
\hline
\end{tabular}

Fonte: Santos (2009a, 2009b, 2010a, 2011a, 2012, 2013a, 2013b); Eugênio (2013); Diário do Nordeste (2012); O Estado Ceará $(2009,2010)$

A somatória dos investimentos do capital privado na cidade (tabela 6) revela que a cidade é um espaço privilegiado para investimentos no âmbito do comércio e dos serviços no Ceará. Além das concessionárias de automóveis de marcas 


\section{PEREIRA, C. S. S. \\ O CENTRO DA CIDADE E AS NOVAS ÁREAS DE CENTRALIDADE NA CIDADE MÉDIA DE JUAZEIRO DO NORTE/CE}

internacionais que chegaram nos últimos seis anos - sobre os quais não se tem dados mais precisos -, os shopping centers e os super e hipermercados fizeram pesados investimentos nas estratégias de expansão das marcas, no processo de instalação de suas unidades em cidades de portes demográficos inferiores a 500.000 habitantes, e com influência regional significativa, além de possuírem um mercado consumidor que, em tese, garantiria os lucros futuros do investimento.

Tabela 6: Juazeiro do Norte. Investimentos das grandes superfícies comerciais. 2009-2013.

\begin{tabular}{lc}
\hline & Investimento (em R\$ milhões) \\
\hline Atacadão & 30 \\
Hiper Bompreço & 35 \\
Maxxi & 30 \\
Assaí & 35 \\
Cariri Garden Shopping & 70 \\
Shopping Juazeiro* & $60^{\star *}$ \\
\hline Total & 260 \\
\hline
\end{tabular}

* Equipamento em construção, ${ }^{* *}$ Custo aproximado.

Fonte: SANTOS (2009a, 2009b, 2010a, 2011a, 2012, 2013a, 2013b)

É importante ressaltar que, na escala da cidade, estes investimentos se concentram nas áreas do Cariri Garden Shopping e no Eixo Juazeiro-Crato, estes sendo os setores urbanos em que o capital nacional e internacional mais investem. São, por conseguinte, as áreas mais valorizadas de Juazeiro do Norte.

Nos últimos anos, tem existido uma significativa valorização do solo urbano tanto no centro principal e nas áreas em que o comércio tem se concentrado, além de alguns setores residenciais "periféricos", provocando práticas de especulação imobiliária pouco presentes, no contexto urbano desta cidade, até 2007. Para se ter uma ideia, em algumas áreas, ocorreu uma valorização de $300 \%$ no preço do metro quadrado enquanto que em outras $1.900 \%{ }^{18}$. Segundo Felipe Neri, diretor Regional do Sindicato da Indústria da Construção Civil (SINDUSCON) da região do Cariri, "para o padrão $A A$, o preço já chegou a $R \$ 6.000,00 / \mathrm{m}^{2}$, e para a faixa $D$, o metro

\footnotetext{
${ }^{18} \mathrm{O}$ bairro Lagoa Seca registrou um aumento de $1.900 \%$ no preço do metro quadrado, saltando e $\mathrm{R} \$$ 15,00 para R $\$ 300,00$, segundo os corretores imobiliários. Matéria completa: "Supervalorização de imóveis chega a $1.900 \%$ em Juazeiro". Diário do Nordeste, 11 de junho de 2011. Disponível em: $<$ http://diariodonordeste.globo.com/materia.asp?codigo=1003728>. Acesso em: 23 mar. 2012. Ver também O Estado (2013).
} 


\title{
PEREIRA, C. S. S. \\ O CENTRO DA CIDADE E AS NOVAS ÁREAS DE CENTRALIDADE NA CIDADE MÉDIA DE JUAZEIRO DO NORTE/CE
}

quadrado fica em torno de $\mathrm{R} \$ 1.200,00 / \mathrm{m}^{2}$ " (O ESTADO, 13/06/2013) ${ }^{19}$. Como divulgado na mídia impressa.

\begin{abstract}
De acordo com o delegado do Creci, na Avenida Padre Cícero, entre o Atacadão e o Cariri Shopping, o metro quadrado chega a custar cerca de $R \$ 600,00$, próximo à pista, e nas quadras residenciais, até $R \$ 200,00$. [...] $\mathrm{O}$ delegado do Conselho Regional dos Corretores Imobiliários (Creci - CE), em Juazeiro, Fagner Canuto Tavares, aponta que em três anos, a área nas proximidades do Cariri Shopping teve uma valorização de até $100 \%$, dentro da média real de investimentos. E foi neste espaço, que houve muitos investimentos em prédios comerciais, pequenas galerias de lojas, além de clínicas médicas. Mas o que tem chamado a atenção são investimentos em construções verticalizadas (SANTOS, 2012c).
\end{abstract}

A mídia local tem noticiado diversas vezes como esse processo tem se desenvolvido e impactado a estruturação da cidade. O preço do metro quadrado, sobretudo no centro da cidade e em algumas áreas próximas a ele, apresentou custos, em 2011 , de até $R \$ 5.000,00$, no patamar dos preços encontrados na capital Fortaleza (SANTOS, 2011), o que tem influenciado o fechamento de muitos pequenos comerciantes devido aos altos custos dos aluguéis, enquanto que alguns deles buscaram outras localizações. O centro principal de Juazeiro do Norte, mesmo com as novas lógicas locacionais das atividades econômicas, ainda é um espaço de intensa disputa, o que reflete no preço do solo urbano desta área.

$O$ reflexo dessa valorização da terra urbana é o fechamento de pequenos comércios de capital local. A chegada dos grandes investimentos encareceu o preço do solo urbano, como se viu anteriormente, e esta supervalorização tornou caro, inclusive no centro da cidade, a permanência de pequenos comércios de capital local. Assim, quando Michel Araújo, presidente da Câmara dos Dirigentes Lojistas de Juazeiro do Norte $(C D L)$ afirma que não vê "problema [n]essa concorrência entre as lojas comercias e os shoppings. Isso desenvolve ainda mais o comércio da cidade" (NETO, 2013), ele só observa o lado, supostamente positivo, da chegada dos investimentos, como se fossem apenas somar aos que já existiam, e não observa os

\footnotetext{
${ }^{19}$ Esses dados a respeito do preço do solo urbano são de entrevistas dos corretores imobiliários noticiados na mídia local. É necessária, ademais, uma pesquisa que busque entender melhor as práticas do setor imobiliário na produção da cidade de Juazeiro do Norte.
} 
reflexos que estes novos investimentos provocaram nos preços dos aluguéis e do solo urbano, tendo como resultado o fechamento de muitas lojas no centro da cidade. No levantamento de campo, foram encontrados 478 estabelecimentos fechados no total, sendo que no centro principal encontram-se 354 (74,05\%), no Pirajá, 91 (14,85\%), na área do Cariri Garden Shopping, 22 (4,60\%) e no Eixo Juazeiro-Crato, 11 (2,30\%). A valorização da terra urbana não se dá apenas em um local onde se implanta o equipamento, mas na cidade inteira, alterando o preço da terra urbana e encarecendo a própria cidade.

De uma maneira paradoxal, ao invés destes novos espaços com expressão de centralidade produzirem uma desvalorização do centro da cidade devido às novas localizações não-centrais da atividades econômicas terciárias, o que assistese é uma igual - ou maior - valorização do centro da cidade. A situação é a seguinte: assiste-se a uma saída de atividades do centro da cidade (desconcentração) para se localizarem em outros "sítios estratégicos", o que resulta em uma complexificação da centralidade na cidade, redefinida no âmbito da estrutura urbana e denotando uma reestruturação da cidade ao mesmo tempo em que há um reforço da centralidade do centro principal, sobretudo pelos papéis históricos e simbólicos que se somam à atividade econômica, por isso que somente esta área é que pode ser entendida como centro. Assim, uma estrutura urbana multi(poli)nucleada se constitui, mas esta estrutura não significa dizer que houve uma descentralização das atividades, mas sim uma desconcentração, conformando novos espaços de centralidade que se hierarquizam e se articulam em rede com o centro a cidade, mas os papéis de comando do centro e a força da sua centralidade para o conjunto da cidade ainda é elevado, embora tenha mudado nos últimos 20 anos.

\section{CONSIDERAÇÕES FINAIS}

A cidade de Juazeiro do Norte faz parte de um processo mais amplo de reestruturação das cidades e urbana que vem atingindo o sistema urbano brasileiro e as cidades médias em particular. Os processos pelos quais esta cidade vem 


\section{O CENTRO DA CIDADE E AS NOVAS ÁREAS DE CENTRALIDADE NA CIDADE MÉDIA DE JUAZEIRO DO NORTE/CE}

passando nas últimas décadas são similares, em alguns aspectos, aos que acontecem em muitas cidades médias brasileiras situadas em diferentes formações socioespaciais e em diferentes regiões do Brasil.

O que se entende como reestruturação da cidade está ligado aos processos que redefinem a centralidade na cidade, provocando o surgimento de novos espaços de concentração de comércio e serviços que passam a ser complementares e concorrentes ao centro da cidade, espaços estes com características diferentes do centro, como os shopping centers, hipermercados e outros semelhantes a estes.

Por meio das estratégias na localização dos agentes econômicos ligados às atividades terciárias, sobretudo aos ramos de lojas de eletrodomésticos, os bancos e os super e hipermercados, percebe-se que existem diferenças entre as localizações destas atividades no espaço urbano, com papéis diferentes quanto a serem vetores da expansão urbana e valorização do solo urbano, mas que de uma forma geral, se articulam para produzir uma cidade paradoxal, que não apresenta mais apenas um espaço com expressão de centralidade, mas outros que possibilitam novas práticas e novos usos da cidade, principalmente em relação ao consumo.

Observou-se que as estratégias locacionais dos novos agentes econômicos ligados o comércio e aos serviços tem afetado o principal espaço de concentração de comércio e serviços, isto é, o centro da cidade. Este espaço da cidade, ainda que tenha diminuído o seu poder de atração, ou melhor, sua centralidade no conjunto da cidade frente às "novas áreas de centralidade", como se observou ao longo do artigo, permanece ainda como o principal espaço de usos e práticas dos agentes sociais, sendo um espaço que poderia ser qualificado como popular, no sentido de que a maior parte da população atual o usa, e não só do ponto de vista econômico, mas também do ponto de vista político e cultural, como é o caso, a título de exemplificação, das romarias e do turismo religioso que acontece anualmente na cidade, tema esse que não foi tratado neste artigo, mas que mereceria um estudo a parte.

Neste sentido, ainda que as discussões a respeito do centro e da centralidade urbana sejam uma temática já consolidada no âmbito dos Estudos Urbanos em geral 
e da Geografia Urbana em particular, o estudo feito aqui procurou argumentar e demonstrar que a análise urbana a partir deste ângulo pode ajudar na compreensão do processo de produção do espaço das cidades brasileiras, em especial as cidades médias, e pode contribuir, também, para entender as ações dos agentes econômicos e suas influências na produção e reestruturação das cidades.

\section{REFERENCIAS}

BAUDRILLARD. J. Hipermercado e hipermercadoria. In: Simulações e simulacros. Lisboa: Antropos, p. 97-101. 1991.

BEAUJEU-GARNIER, J. Méthode d'étude pour le centre des villes. Annales de Géographie, Paris, v. 74, n. 406, p. 695-707, 1965.

BONNET, J.; TOMAS, F. Centre et périphérie: Eléments d'une problématique urbaine. Revue de géographie de Lyon, Lyon, v. 64 n. 1, p. 3-12, 1989.

CASTELLS, M. La intervención admnistrativa en los centros urbanos de las grandes ciudades. Papaers: Revista de Sociologia, Barcelona, n. 11, p. 227-250, 1979. - Innovation technologique et centralité urbaine. Cahiers de recherche sociologique, cidade, v. 6, n. 2, p. 27-36. 1988.

CEARÁ. Secretaria de Planejamento e Coordenação, Superintendência do Desenvolvimento do Estado do Ceará. Pesquisa sobre as condições de vida da população de baixa renda das cidades de Crato e Juazeiro do Norte-Ceará. Fortaleza, 1980.

CHALAS, Y. Centre, centralité et polycentrisme dans l'urbanisation contemporaine. Les Cahiers du Développement Urbain Durable, Université de Lausanne, n. 11, p. 23- 41, 2010.

CORRÊA, R. L. O espaço urbano. São Paulo: Ática, 1989.

DANTAS JÚNIOR, A. Supermercados entram com força no interior do Ceará. Diário do Nordeste. Fortaleza, 17 ago. 2010. Disponível em: < http://diariodonordeste.globo.com/materia.asp?codigo=833437>. Acesso em. 12 jan. 2013. 
FAINLICHT, M. Le citadin et la centralité. Revue Urbanisme, Paris, n. 120-121, p. 21-23, 1970.

GARROCHO-RANGEL, C. F.; CAMPOS-ALANÍS, J. Organización espacial del sistema bancario dentro de la ciudad: estrategia territorial, accesibilidad y factores de localización. Economía, Sociedad y Territorio, México, v. 10, n. 33, p. 413-453, 2010, pp. 413-453.

INSTITUTO BRASILEIRO DE EXECUTIVOS DO VAREJO E DO MERCADO DE CONSUMO (IBEVAR). Ranking 2012. As 100 maiores empresas do varejo brasileiro. Disponível em: <http://www.esperienza.com.br/ibevar/f01/pdf/pesquisa-epublicacoes/ranking-ibevar-novo-indd-2012.pdf>. Acesso em: 31 ago. 2013.

INSTITUTO BRASILEIRO DE GEOGRAFIA E ESTATÍSTICA (IBGE). Regiões de Influência das Cidades, 2007. (REGIC). Rio de Janeiro, 2008.

KAYSER, B. O geógrafo e a pesquisa de campo. Seleção de Textos, n. 11. São Paulo: Teoria e Método. Associação dos Geógrafos Brasileiros, p. 93-104, 1985.

LABASSE, J. Signification et avenir des centres. Revue Urbanisme, Paris, n. 129121, p. 9-17, 1970. 46, 1965.

. Centre-ville et réalités urbaines. Economia et humanisme, n. 161, p. 40-

LEFEBVRE, H. A revolução urbana. Belo Horizonte: EdUFMG, 2008. [1970].

LÉVY, J. Centre-ville: toutes directions. Espaces Temps, Lausanne, n. 33, p. 50-58, Voyage au centre de la ville. Éloge de l'urbanité. 1986.

METTON, A. Centre-ville et périphéries. Complémentarité ou concurrence commerciale? Bulletin de l'Association de Géographes Français. Paris, p. 263276, 1989.

MONNET, J. Les dimensions symboliques de la centralité. Cahiers de Géographie du Québec. v. 44, n. 123, p. 399-418, 2000. 


\section{O CENTRO DA CIDADE E AS NOVAS ÁREAS DE CENTRALIDADE NA CIDADE MÉDIA DE JUAZEIRO DO NORTE/CE}

NETO, J. B. Shoppings com investimentos de R\$130 mi. O Povo, Fortaleza,

Economia, 21 de nov. 2013. Disponível em: http://www.opovo.com.br/app/opovo/economia/2013/11/21/noticiasjornaleconomia,31 66146/shoppings-com-investimentos-de-r-130-mi.shtml. Acesso em: 4 dez. 2013.

NETZ, C. Tenco investe $R \$ 70$ mi em shopping no Cariri. O Estado de São Paulo, São Paulo, Economia e Negócios, 21 jul. 2010. Disponível em: <http://www.estadao.com.br/noticias/impresso,tenco-investe-r-70-mi-em-shoppingno-cariri,583939,0.htm>. Acesso em: 12 mar. 2013.

PERNELLE, J. Une méthodologie d'etude du centre-ville. Revue Urbanisme, Paris, n. 117, p. $45-47,1970$.

RENDU, P. Rôle fonctionnel du centre. Revue Urbanisme, Paris, n. 120-121, p. 1820, 1970.

SALGUEIRO, T. B. Do comércio à distribuição: roteiro de uma mudança. Oeiras: Celta Editora, 1996.

SANTOS, M. Contribuição ao estudo dos centros de cidades: o exemplo da cidade de Salvador. Boletim Paulista de Geografia, São Paulo, n. 12, p. 17-30, 1959.

SANTOS, E. Assaí inaugura hoje nova loja no Cariri. Diário do Nordeste. Fortaleza, 09 jul. 2013a. Disponível em: <http://diariodonordeste.globo.com/materia.asp?codigo=1289696>. Acesso em. 13 jul. 2013.

Comércio segue a todo vapor em Juazeiro do Norte. Diário do Nordeste, Fortaleza, 03 fev. 2013b. Negócios. Disponível em: <http://diariodonordeste.globo.com/materia.asp?codigo=1229901>. Acesso em 07 jun. 2013.

Juazeiro descentraliza comércio para os bairros. Diário do Nordeste, 25

set. de 2012a. Disponível em: <http://diariodonordeste.globo.com/materia.asp?codigo=1185086>. Acesso em: 25 fev. 2013.

Fortaleza, 26 jul. 2012b. Regional. Disponível em: < 


\section{O CENTRO DA CIDADE E AS NOVAS ÁREAS DE CENTRALIDADE NA CIDADE MÉDIA DE JUAZEIRO DO NORTE/CE}

http://diariodonordeste.globo.com/materia.asp?codigo=1152860 >. Acesso em: $01 \mathrm{ag}$. 2012.

. Valorização imobiliária chega a 300\% em Juazeiro. Diário do Nordeste, Fortaleza, 04 abr. 2012c. Disponível em: $<$ http://diariodonordeste.globo.com/materia.asp?codigo=1122603\&fb_source=messa ge>. Acesso em: 27 ago. 2012.

- Hiper Bompreço abre nova loja em Juazeiro. Diário do Nordeste, Fortaleza, 28 jul. 2011a. Disponível em: <http://diariodonordeste.globo.com/materia.asp?codigo=1017605> Acesso em: 14 mar. 2012.

Supervalorização de imóveis chega a $1.900 \%$ em Juazeiro. Diário do Nordeste, Fortaleza, 29 jun. 2011b. Mercado. Disponível em: <http://diariodonordeste.globo.com/materia.asp?codigo=1003728>. Acesso em: 14 abr. 2012.

- Walmart investe $R \$ 30$ milhões em Juazeiro. Diário do Nordeste, Fortaleza, 20 jul. 2010a. Caderno Negócios Disponível em: <http://diariodonordeste.globo.com/materia.asp?codigo=822950>. Acesso em: 23. mai. 2012.

- Grupo Carrefour Inaugura Atacadão no Ceará. Diário do Nordeste, Fortaleza, 13 mar. 2009. Disponível em: <http://diariodonordeste.globo.com/materia.asp?codigo $=621808>$ Acesso em: 30 mai. 2012.

SPOSITO, M. E. B. Segregação socioespacial e centralidade urbana. In: VASCONCELOS, P. A.; CORRÊA, R. L.; PINTAUDI, S. M. A cidade contemporânea: segregação socioespacial. São Paulo: Contexto, p. 61-93. 2013.

Multi(poli)centralidade urbana. In: SPOSITO, E. S.; SANT'ANNA NETO, J. L. (Org.). Uma Geografia em Movimento. São Paulo: Expressão Popular, p. 199228. 2010a.

. O desafio para o estudo das cidades médias. XI Seminário Internacional da Red Iberoamericana de Investigadores sobre Globalización y Território (RII). Mendoza, 2010. Anais... Mendoza, Argentina, p. 1-18, 2010c. 
SZULC, N. Centre historique et centralité. Revue Urbanisme, Paris, n. 147-148, p. 98-101, 1975.

TOURINHO, A. de O. Do Centro aos centros: bases teórico-conceituais para estudo da centralidade em São Paulo. 2004. 438f. Tese (Doutorado em Arquitetura e Urbanismo), Centro de Pós-graduação, Estruturas Ambientais Urbanas, Universidade de São Paulo, São Paulo. 2004.

VARGAS, H. C. Shopping Centers: Novas Relações Entre A Atividade Comercial e O Espaço Urbano. In: V Encontro Nacional da ANPUR, 1993, BELO HORIZONTE. Encontro Nacional de Anpur, 5. Belo Horizonte: ANPUR, v. 2. p. 736-747. 1993.

VILLAÇA, F. Espaço intra-urbano no Brasil. 2 ed. São Paulo: Studio Nobel, 2009. 